\title{
Application of Integrated GNSS/Hydroacoustic Measurements and GIS Geodatabase Models for Bottom Analysis of Lake Hancza: the Deepest Inland Reservoir in Poland
}

\author{
Dariusz PopielarczyK ${ }^{1}$ and Tomasz Templin ${ }^{1}$
}

\section{Introduction}

Since almost $40 \%$ of the world's largest lakes have not yet been studied, their volumes are therefore approximated (ShIKLOMANov and RodDA 2003). The most challenging situation is with smaller reservoirs and inland lakes. Due to high costs and time required for acquiring bathymetric data some inland reservoirs have not been investigated. There are some probes to estimate certain morphometric parameters using existing, publicly available datasets (HoLlister and Milstead 2010; Hollister et al. 2011).

The acquisition of geophysical and hydrographic data is of fundamental importance for ensuring safety of life on Earth. Hydrography deals with the measurement and description of the physical features of the seas, lakes and rivers for the primary purpose of safe navigation and environmental protection (INTERnational Hydrographic Organization 1994). Whilst the instrumentation is constantly developing and technology is continually changing the general idea of performing bathymetric and geophysical surveys is still the same (Hydrographic Surveys Division 1878; Hawley 1931; National Oceanic and Atmospheric Administration 1976; Ingham 1992; International Hydrographic Organization 2005). Hydrographic high quality data are now being acquired in inland shallow water using high frequency single or

1 Department of Satellite Geodesy and Navigation, University of Warmia and Mazury in Olsztyn, Heweliusza 5, 10-724 Olsztyn, Poland. E-mail: dariusz.popielarczyk@uwm.edu.pl; tomasz.templin@uwm.edu.pl multibeam echosounders, airborne laser scanning, side scan sonars, sub bottom profilers and multiparameter sensors. The data provided by these systems gives information about bathymetry, geomorphology and lake floor geologic processes (ClARKE 1996; YANG and ZHANG 2011). The authors describe an open and flexible solution of acquiring, storing, processing, and publishing results of inland hydrographic measurements with the use of modern, integrated Global Navigation Satellite Systems (GNSS) and Single Beam Echo Sounder (SBES) methods.

The deepest inland reservoir in the central part of European Depression called Lake Hancza, located in the northeastern part of Poland in the Suwalki Landscape Park was chosen as the study area (Fig. 1). The maximum depth and basic morphometry of this oligo-mesotrophic lake differ depending on the bibliography. The first depth measurements described by Sledzinski in 1927 were done from an ice platform with the use of a hemp rope. The maximum depth was estimated as $104.5 \mathrm{~m}$ (SLEDZINSKI 1927). The next bathymetric measurements were done in July 1930 by Professor Edward Ruhle. He reported that the maximum depth of the lake was $108 \mathrm{~m}$ (RuHLE 1932) with the water level of $227.2 \mathrm{~m}$ above the sea surface. The maximum depth provided by Stangenberg was $108.5 \mathrm{~m}$ (STANGENBERG 1936, 1938).

A Polish-Hungarian team of scientists: Jozsa, Tatrai, Gyore and Kozlowski conducted a bathymetric survey using hydroacoustic equipment in the years 2000-2007 (Jozsa et al. 2008). The results of their work indicated that the maximum depth of Lake Hancza was $112 \mathrm{~m}$. Nevertheless, their 

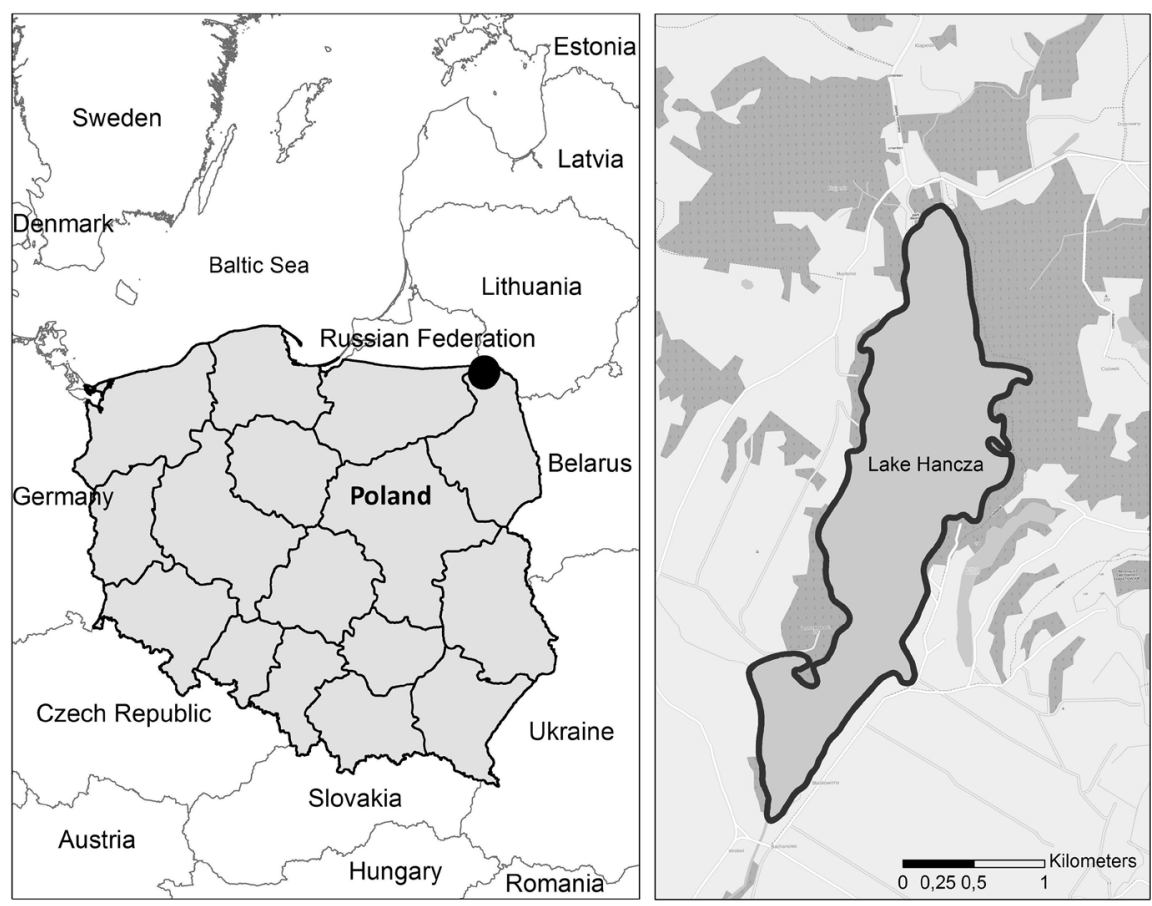

Figure 1

Lake Hancza- the location of study area

measurements were not preceded by a study of the sound velocity distribution in the water and the calibration of the SBES. Additionally, the water level was not determined during these measurements.

Further records provide divergent information about the morphometry and maximum depth of the lake. This information was not clearly confirmed by later scientific study. The existing analogue map is still based on the old Ruhle and Stangenberg surveys performed in 1930s. On the other hand, precise bottom digital elevation model (DEM), reliable information about the current bathymetry and basic morphometric parameters are very important for researchers and have many applications in hydrological, geomorphological, and biological studies (Moore et al. 1991; Hutchinson 1957; Hollister and MilsteAd 2010). An accurate DEM is also useful in bathymetry, construction of the lake floor morphology and analysis of area and volume changes (LEON and CoHEN 2012).

The increasingly interdisciplinary character of scientific research requires cooperation of scientists and engineers in many fields. Recent progress in measuring equipment, Geographic Information
Systems (GIS) and Science, databases and wireless technology has produced large amount of geospatial data. GIS in an powerful tool for storing, integrating, analysis and visualization this data (SHEKHAR 2008).

Almost all today's computers are now connected to the network. The use of the web as a dissemination medium for maps opens many new opportunities, such as distributed data sources and sharing of geographic information (KRESSE and DANKo 2012). The GeoWeb is popular term describing how to use distributed technology and network services to present spatial data interactively (LongLey et al. 2011). The most common methods of publishing data are: web mapping, WebGIS with GIS servers and Virtual Globes (Tsou 2004; Kulawiak et al. 2010; Chien and Keat Tan 2011).

The aim of this study was to elaborate an accurate and reliable DEM for Lake Hancza based on an integrated satellite and precise hydroacoustic surveys. The DEM and historical bathymetric datasets were incorporated into a personal geodatabase for comparison and visualization. Products were distributed using web mapping as a means of increasing 
cooperation and exchange of data between researchers and engineers in many fields.

\section{Methodology: Experimental Procedures}

The methodology proposed and applied in the research consists of performing experimental bathymetric measurements on Lake Hancza, elaborating hydrographic raw data, analyzing historical and new elaborated spatial bottom models and demonstrating the technology of publishing geospatial data. Figure 2 presents flowchart describing the methodology used for Lake Hancza DEM analysis.

Construction of a DEM of the lake bottom requires obtaining both position and depth raw data. GNSS positioning techniques integrated with single beam hydroacoustic technologies were used to

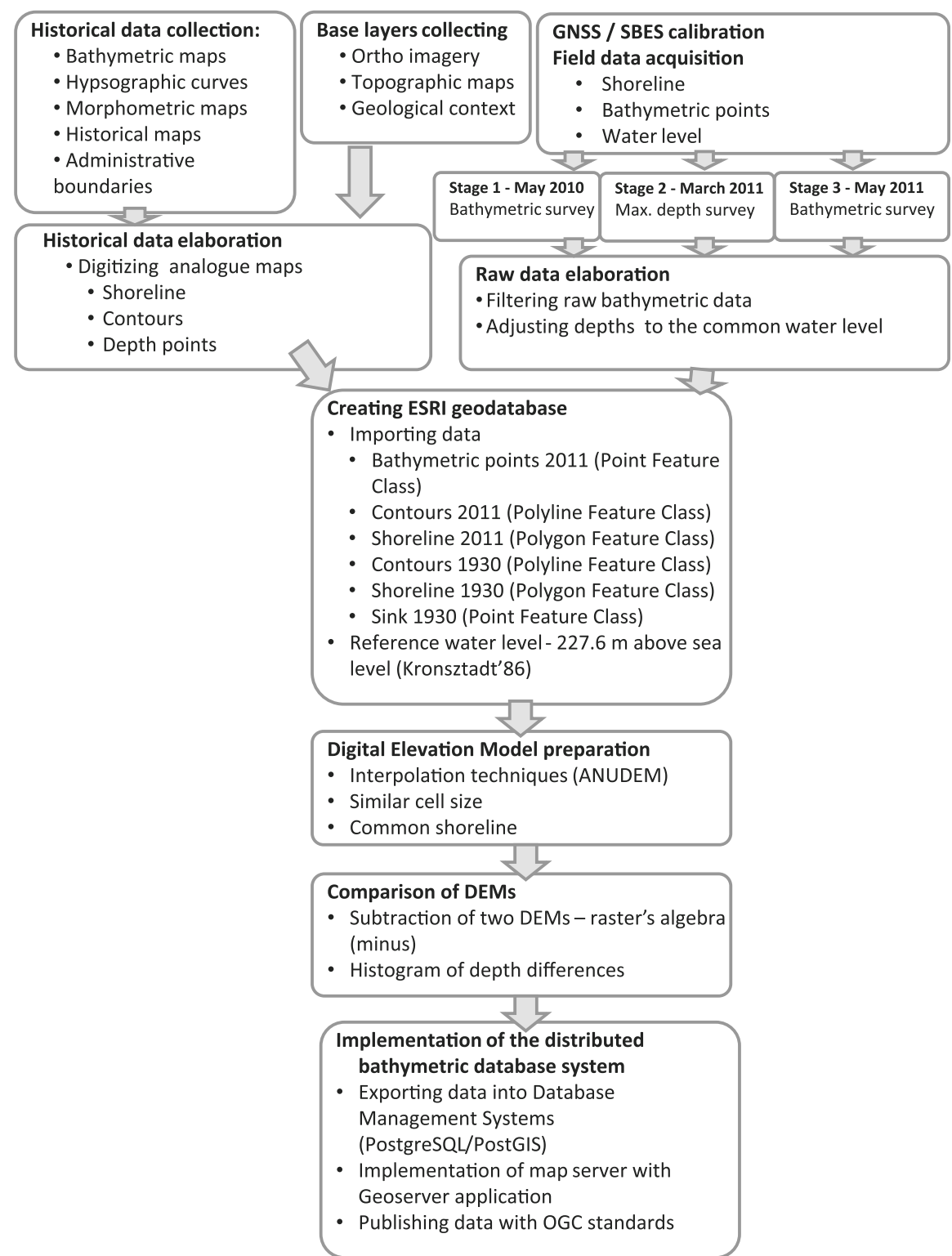

Figure 2

Flowchart describing the methodology used for Lake Hancza DEM analysis 
investigate the Lake Hancza bottom. The field study was divided into three survey stages. The first preliminary bathymetric survey of the central deepest region of Lake Hancza was performed in May 2010. After this part, the spatial bottom model was computed and the deepest region was estimated using Environmental Systems Research Institute (ESRI) ArcGIS software. The second part of the project was conducted in March 2011. In this part, both classical and hydroacoustic surveys were done directly from the ice platform to confirm the maximum depth. The third part of the field project realization was done in May 2011. This part included a bathymetric survey of the remaining region of the lake.

\subsection{GNSS and Hydroacoustic Integrated Techniques}

The quality of the DEM is basically a function of the accuracy of individual survey points, field survey strategy and the method of interpolation (HeRITAGE et al. 2009). The Real Time Kinematic (RTK) technique is most accurate for precise dynamic positioning. The practical experiments show that even cost-effective Differential Global Positioning System (DGPS) measurements of DEM give an accuracy sufficient in most GIS projects (СIECKO et al. 2006; PopielarczyK and OszcZAK 2002).

The Integrated Bathymetric System used in the Lake Hancza project basically consists of: an RTK/DGPS/GNSS positioning, a hydroacoustic bottom detection system, special hydrographic GNSS, GIS software and an hydrographic motorboat (Popielarczyk 2002, 2011). The system is presented in Fig. 3.

To achieve high accuracy in the digital representation of the lake bottom, a hydrographic SBES and RTK/DGPS geodetic Global Positioning System (GPS) receivers were used. Topcon HiPer Pro GNSS and Thales Mobile Mapper GPS receivers operating in RTK/DGPS mode were used for determining the boat position during soundings. DGPS technique was used for navigation and RTK was used for spatial data collection. RTK positioning was determined based on the NAWGEO service of Polish reference stations network called ASG-EUPOS (Active Geodetic Network-European Position Determination System). This system has prepared the standards for geodetic reference network for 15 countries in Central and Eastern Europe in order to establish a unified infrastructure for positioning services. The estimated horizontal accuracy of carrier phase kinematic navigation is $0.03 \mathrm{~m}$ (Bosy et al. 2007; RYCZYwolski et al. 2008). Instead of the RTK Virtual Reference Station (VRS) service, KODGIS kinematic DGNSS service with an estimated accuracy of $0.2-0.5 \mathrm{~m}$ can also be used. It is also possible to use the post-processing network code DGPS mode with an accuracy better than $0.3 \mathrm{~m}$ (BAKULA 2010) or a network RTK carrier phase DGPS in cases where centimeter accuracy level is required (CANNON et al. 2001). In accordance with the International Hydrographic Organization (IHO) S-44 Standards for Hydrographic Surveys, where the horizontal accuracy for Special Order areas is $2 \mathrm{~m}$, the achieved accuracy is sufficient for the majority of bathymetry surveying (International Hydrographic Organization 2008). During the measurements on Lake Hancza, RTK corrections in the Radio Technical Commission for Maritime Services (RTCM) format were sent via General Radio Packet Services (GPRS) to the rover receivers. The Global System for Mobile Communication (GSM) terminal for data transmission was used. The GPS antenna was mounted vertically over the echo sounder transducer, which was placed on the left side of the hydrographic boat. Therefore, no horizontal offsets need to be applied. ArcMap v. 9.2 by ESRI Inc. was used for navigation through the measurement profiles. The basic measurement profiles were designed in the East-West directions at spatial sampling of $20 \mathrm{~m}$ against the background of a coastline layer. The coastline was elaborated on the basis of satellite imagery and aerial photos complemented by satellite and classical geodetic measurements. The use of aerial or satellite photographs as the source of data on the coastline course also allows conducting detailed, short- and longterm observations of the changes (TEMPLIN and PopielarczyK 2011; Kim et al. 2008). The position determined in real time with a $1 \mathrm{~s}$ sampling interval allowed precise navigation of the boat along the measurement profiles. Additionally, there was a local RTK/DGPS reference station set up only for the dedicated project in order to record raw satellite observations. The coordinates of the local station 


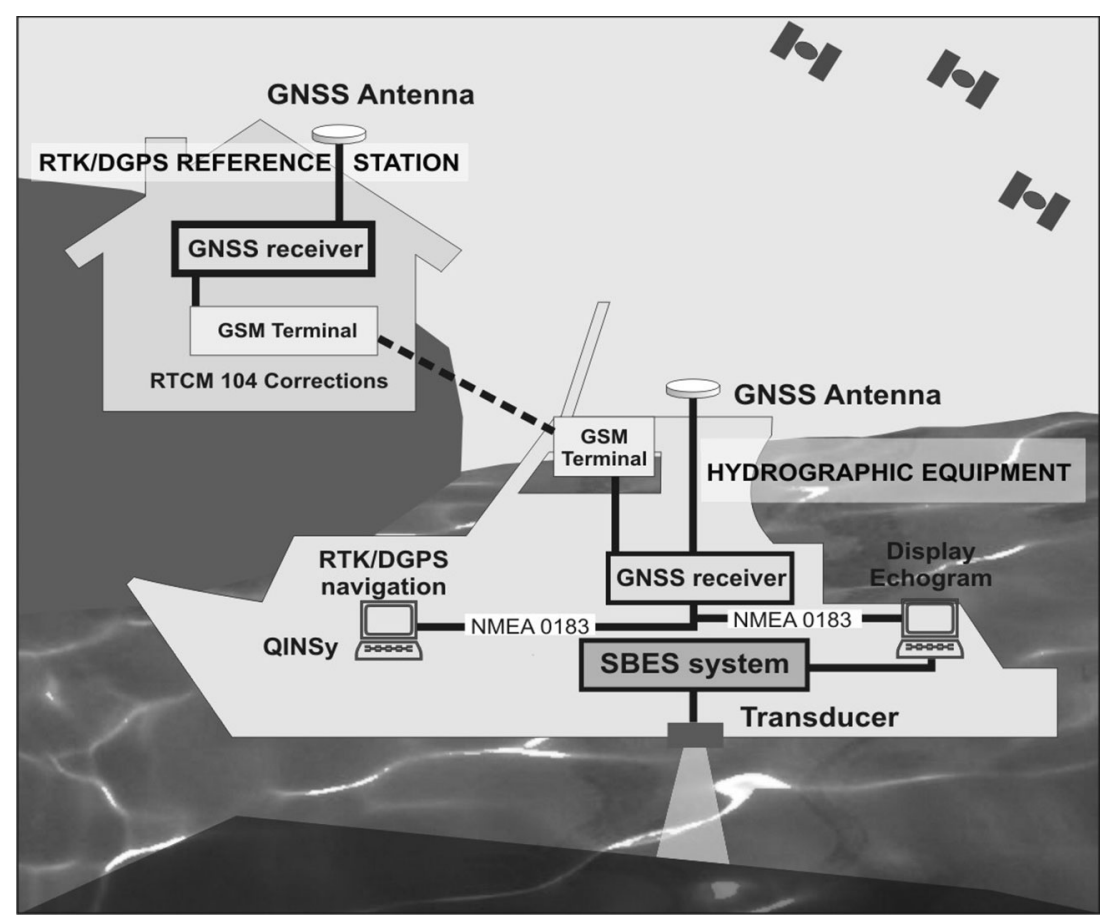

Figure 3

Integrated bathymetric system

were calculated using static DGPS technique using the permanent reference station located in Suwalki (SWKI). The local GPS raw data were used for water level calculation for each of the measurement stages. In inland bathymetry, the reference water level can change slightly in time, therefore, all hydrographic raw data had to be brought to the common water level.

Two single-beam echo sounders (SBES): Simrad EA501P (200 kHz) and Reson NS 515 (33/200 kHz) were used to conduct depth measurements. In a bathymetric survey it is necessary to perform hydroacoustic system calibration. The sound speed in water has a fundamental influence on the accuracy of depth measurements using hydroacoustic methods. The speed of sound in water usually varies due to depth and season. In lakes there is a thin water layer called thermocline in which the temperature changes rapidly with depth. Especially in the summer, the thermocline affects sudden changes in the speed of sound in water (DARBYSHIRE and EDwARDS 1972). Under such conditions, SBES calibration is necessary to increase depth measurement accuracy. The vertical distribution of the ultrasound waves' speed in water should be measured using the Sound Velocity Profiler (SVP) or the CTD sonde (conductivity, temperature, depth). Before commencement of the sounding, tests of water parameters were conducted to determine the sound propagation speed in water. Before hydroacoustic sounding of Lake Hancza, a YSI 600R instrument was used for water quality sampling. Conductivity and temperature were tested and the YSI2SS software was used for computation of the sound speed in water on the basis of the formula developed by Clay and Medwin (1977). On the basis of results from the sound speed in water tests and a bar check calibration, the hydrographic systems were calibrated for depth measurements in Lake Hancza.

\subsection{Acquisition of Bathymetric Data}

After testing the correctness of reference station performance, precise RTK/DGPS positioning navigation and following calibration of the single beam depth measurement system, the field survey work was started. The bathymetric surveys were conducted in 
three stages over six measurement days (Table 1). During the first stage of the project, the central, deepest area of Lake Hancza was investigated. The sound speed profile in a water column was precisely determined to ensure the correct depth measurements. The value of sound speed from 0 to $60 \mathrm{~m}$ was between 1,458 and $1,422 \mathrm{~m} / \mathrm{s}$, while the water temperature ranged from 13.12 to $4.27{ }^{\circ} \mathrm{C}$ depending on the depth. The estimated by Clay and Medwin formula sound speed profile in water was entered directly into the SBES systems. The SBES echo sounder was also controlled by conducting a barcheck calibration (US ARMY CORPS OF ENGINEERS 2003).

The second part of the survey was conducted on 12 March, 2011. The classical depth determination and hydroacoustic surveys were done directly from the ice sheet to confirm the correct value of the maximum depth. Hydroacoustic measurements were performed using Simrad EA501P and Reson NS 515 echosounders and a special calibrated lead sounding line. The measurements were done in the central, deepest region of the lake. This area was indicated after spatial analysis of the bottom model elaborated from the first stage bathymetric data. A depth study was conducted at the five locations placed at the deepest cross-section profile on the bottom. The horizontal distances between the measurement points were 15-20 m apart. The water parameters were measured using a YSI 600R CTD appliance. The calculated velocity of sound speed in the water was used to calibrate the bathymetric equipment. The water temperature varied from $0.86{ }^{\circ} \mathrm{C}$ under the ice sheet to $3.30{ }^{\circ} \mathrm{C}$ at a depth of $60 \mathrm{~m}$. The value of the sound speed was between 1,406 and 1,418 m/s. To confirm hydroacoustic measurements, a hand-held calibrated lead sounding line was used to measure the maximum depth.

The final field data acquisition was conducted on 6-8 May 2011. The bathymetric measurements were performed using a Reson NS 515 dual frequency SBES system and Topcon HiPer Pro GNSS receiver. The calibration of the hydrographic device procedure was the same as during the first and second stage. The sound speed in the water column varied between 1,438 and $1,421 \mathrm{~m} / \mathrm{s}$, where the water temperature ranged from $8.00{ }^{\circ} \mathrm{C}$ under the water surface to
$4.00{ }^{\circ} \mathrm{C}$ at a depth of $60 \mathrm{~m}$. After the last stage of the field survey, the hydrographic raw data was corrected in post-processing mode according to the bar-check procedure.

\subsection{Raw Data Elaboration}

The three stages of hydroacoustic sounding took 6 days of field work. After conducting integrated measurements on Lake Hancza, the recorded bathymetric data were elaborated. All collected hydrographic and GPS raw data were initially processed and edited in the field and then recorded for further elaboration. Hydroacoustic raw data, along survey lines, were recorded as binary echogram files. Each echogram contains bottom visualization, depth, position and information about the SBES configuration. The graphical bottom representation was used for depth raw data verification using special applications originally developed by authors (Echo Converter and Echo View).

During bathymetric and geodesic surveys on Lake Hancza, the water level changed slightly over the different stages. It was necessary to adjust the verified hydrographic data to the common water level. The specific character of the reservoir caused only decimeter changes in the water level. To determine the final water level, GPS antenna ellipsoidal heights computed in On The Fly (OTF) post-processing mode and static measurements on the ice sheet were considered. The vertical map datum in Poland is based on the Kronsztadt'86 (normal heights above sea level). All observed ellipsoidal heights were transformed to the normal heights using the Polish gravimetric quasi-geoid model 2000.

During the first stage of hydroacoustic surveys, the normal height was $227.90 \mathrm{~m}$ above sea level. The height of the ice platform in the second stage was calculated using the static GPS technique. The static GPS measurements were performed using three GPS reference stations: the local reference station (dedicated for the Lake Hancza project) and two ASGEUPOS reference stations. The normal height of ice was $227.6 \mathrm{~m}$ and the maximum investigated depth was $105.7 \mathrm{~m}$ (hydroacoustic SBES survey confirmed by calibrated lead line). During the third part of bathymetric surveys, the water level was determined as being $227.65 \mathrm{~m}$ above sea level. 
As a result of processing the raw measurement data, the set of points was converted to common (lowest during three survey stages) water level (227.6 $\mathrm{m}$ above sea level). These points formed the database set for development of the DEM of Lake Hancza bottom.

\section{Design and Algorithms}

The database is the most important part of every GIS, because of the cost of creation and maintenance and also the impact on all analysis, modeling and decision-making activity (LONGLEY et al. 2011). Welldefined database models have a strong influence on future database usage and should be universal and satisfy the needs of most potential users. Scientists from various disciplines have different knowledge, methodology and applications. As BreUnig and ZlATANOVA (2011) state, "Applications relying on geomodels have distinct needs: some applications may require models only for visualization, while others may require models for analysis and statistics".

Environmental monitoring and natural resource management require access to spatial and non-spatial data. Currently, almost all database vendors offer spatial information capabilities in their products. On the other hand, GIS software developers have taken advantage of the concept of processing spatial data within a database environment (YEUNG and BRENT 2007). Recently, there has been extensive use of Relational Database Management System (RDBMS), such as the personal geodatabase format from ESRI software for collecting and managing data (CHESNAUX et al. 2011). ESRI ArcGIS software is also a popular way for $3 \mathrm{D}$ modeling and visualizing the spatial context of the data.

\subsection{Bathymetric Geodatabase Design}

Lake bathymetry monitoring has become more attractive using recent advances in GNSS, hydroacoustic techniques, database management systems, remote sensing data and GIS software. A typical problem with modern measuring sensors is finding a way to quickly and efficiently integrate, store and manage raw measurement data. In this study, the spatial database implemented in an ESRI personal geodatabase format was a repository of bathymetrical and other spatial and non-spatial information. The geodatabase was organized into spatial datasets, terrain datasets and raster/grid catalogs. The structure has all datasets stored within Microsoft Access, which is a RDBMS customized for storing spatial data structures. A geodatabase provides more functionality than standard GIS file formats and is a convenient way to manage the objects and relationships. An ESRI geodatabase is also a good starting point for creating more sophisticated data models in the future. Additionally, in June 2011 ESRI released the File Geodatabase Application Programming Interface (API). This API allows developers to work with file geodatabases, create independent applications to view or modify data stored in a file geodatabase and exchange data with different Database Management Systems (DBMSs).

The Lake Hancza project's geodatabase was developed with ArcGIS Desktop and ArcMap, version 10, from ESRI. To complete the database creation process, all historical data and information collected by different public and private organizations was examined. Historical maps, bathymetric plans, studies and other analog paper sources were digitized and imported into the geodatabase as digital objects. All GIS datasets and structures were created in the Polish National Coordinate System "2000" Zone 8.

New features from the integrated GNSS/hydroacoustic measurements were created. The edited data points in the XYZ text file format were converted into an ESRI point feature class geodatabase. The point feature class contains the $X$ and $Y$ horizontal coordinates and the elevation and depth values associated with each collected point. Figure 2 summarizes a number of the sources that are entered into the spatial database.

\subsection{DEM Generation}

There are a number of methods for modeling 3D data, such as terrain models. The most popular among them is the regular grid surface (Grid) and Triangulated Irregular Network (TIN). Both of them are commonly used for creating and representing surfaces in GIS (EL-Sheimy et al. 2005). 
The Lake Hancza DEM was elaborated using GIS software, which provides an ideal environment for data conversion, geo-referencing, profile extraction, interpretation and visualization. The DEM was generated with the use of ESRI ArcGIS 10 with the 3D Analyst/Spatial Analyst extension. Bathymetric parameters such as volumetric and area calculations were derived using the TIN surface model which was created using the collected bathymetric data points and the lake boundary inputs (Fig. 4). The TIN consists of connected data points that form a network of triangles representing the bottom surface of the lake.

Contours, depth ranges, and the shaded relief map were derived from a DEM grid. This grid was created using the ArcMap Topo to Raster Tool and had a spatial resolution of $5 \mathrm{~m}$. The contours were created at a $5-\mathrm{m}$ sampling interval using the ArcMap Contour Tool. The contour lines were edited to improve the accuracy and general smoothness of the lines. The contours were then converted into a polyline feature class and attributed to show 5-m depth ranges across the lake.

\subsection{Comparison of Digital Elevation Models}

Spatio-temporal analysis of consecutive bathymetric measurement campaign will help to understand the physical and ecological dynamics of lakes. They are an important indicator for environmental monitoring, such as coastline changes, lake and reservoir sedimentation, etc. This information is also required for additional analysis of water ecosystem functioning, life times of reservoirs, monitoring of chemical and physical water parameters and for building advanced databases.

This study of the Lake Hancza project evaluated a DEM generated from historical contour lines and another DEM obtained from newly-acquired bathymetric data. To enable their comparison, both DEMs were generated with a $5 \mathrm{~m}$ spatial resolution. The DEM derived from contour lines was prepared using data such as elevation points, contours line and bathymetry from the old Ruhle map generated with $1: 25,000$ scale and $10 \mathrm{~m}$ contour lines height distance. The second, a new DEM was created from bathymetric points and the lake boundary. All data were taken from the ESRI geodatabase. A method based on surface adjustment Topo-to-Raster module from ArcGIS 10 was used. This interpolation method was specifically designed for the creation of hydrologically-correct DEMs. It is based on the ANUDEM program developed by HuTCHINSon (1989). DEMs of Lake Hancza derived from

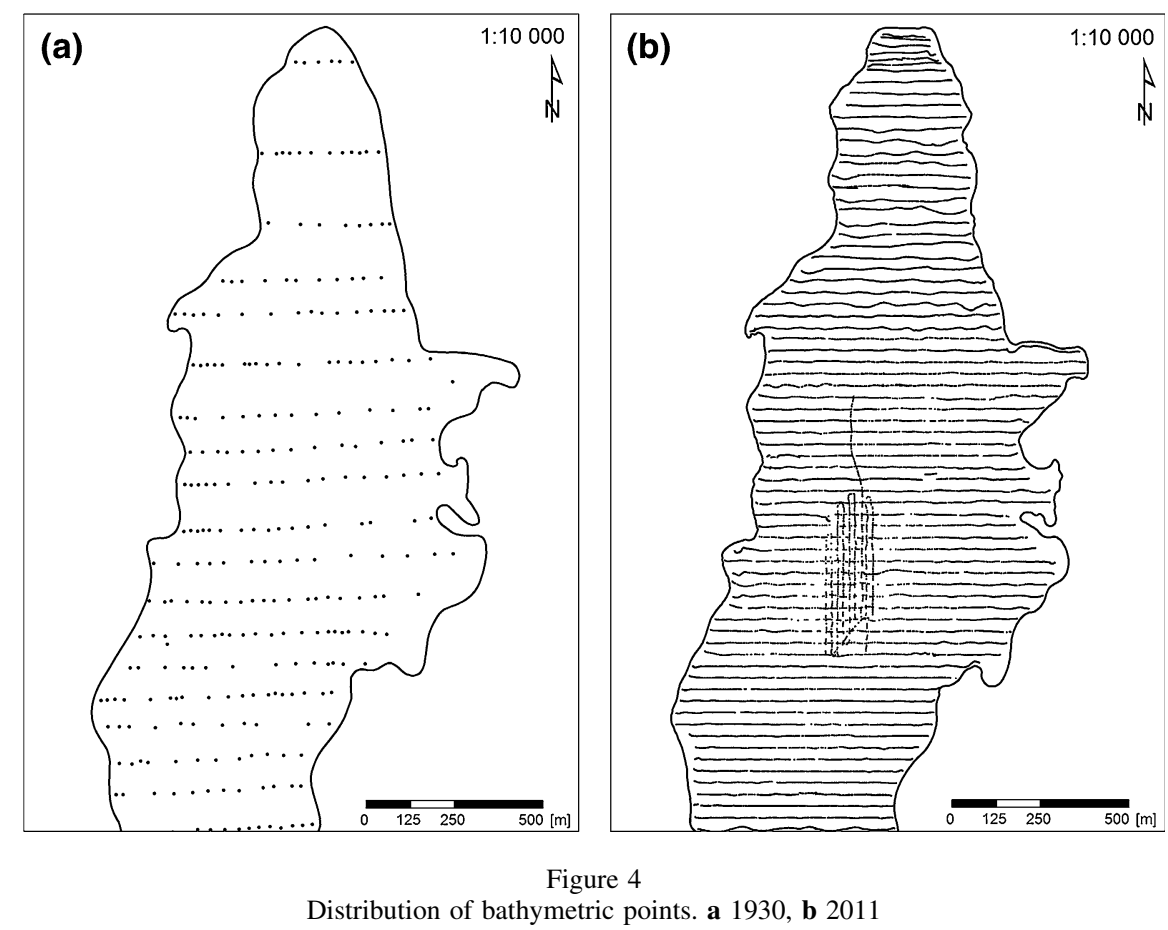


1930 and 2011 and the subtraction result are presented in Fig. 5.

The geometrical way to show statistic bottom subtraction results is to use an histogram. Figure 6 shows the histogram of differences of the bottom models. Differences in the height of a point on the bottom elevation model determines the histogram dispersion. The vertical axis shows the number of cells of the corresponding differences. The number of 0 differences, lying on the right side of the histogram curve appear to be an informative index for bottom changes. The mean of the curve maximum (peak of the plot) indicates a negative difference at the level of $-2.30 \mathrm{~m}$. The mean value of differences and location of zero mean that the historical DEM of the bottom was generally lower than the new one.

\section{Lake Hancza-Implementation of the Distributed Bathymetric Database System}

The broad range of disciplines within environmental science requires a common way to exchange data and ideas. Nowadays, scientists and environmental engineers expect to be able to view maps and other cartographic products interactively, on the web. They need easy solutions to share the results of their research in the network and connect information from external online sources. Standardization is necessary to bring the different data sources together and visualize them in the way the user wants. To ensure the interoperability between the various services, many standards were developed and spatial interfaces standardized by the Open Geospatial Consortium (OGC). They are explored in an OGC Reference
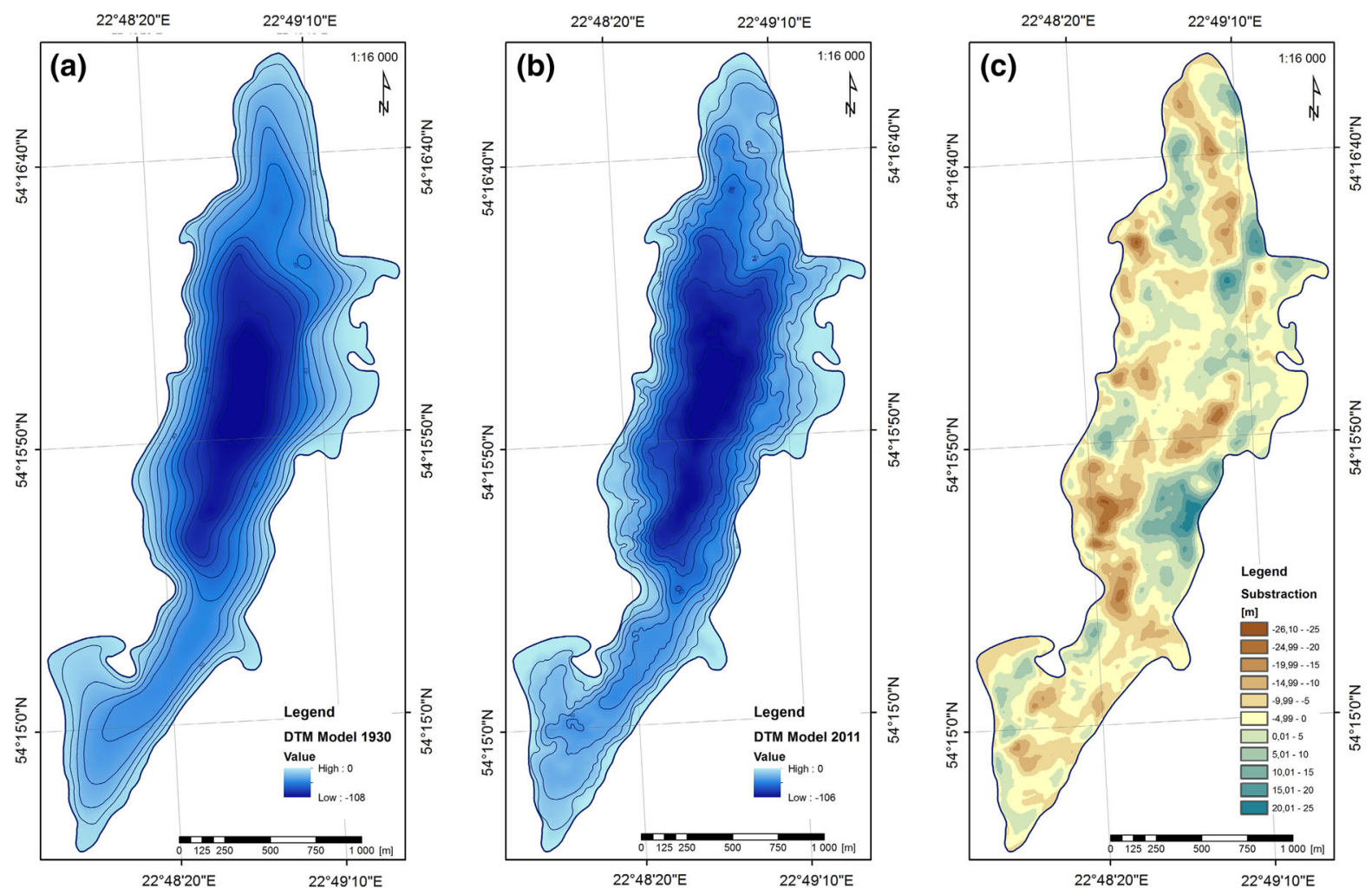

Figure 5

Bathymetric models of Lake Hancza (reference water surface level-227.6 m above sea level—Kronsztadt'86). a DEM 1930; b DEM 2011; c subtraction of two bathymetric models 


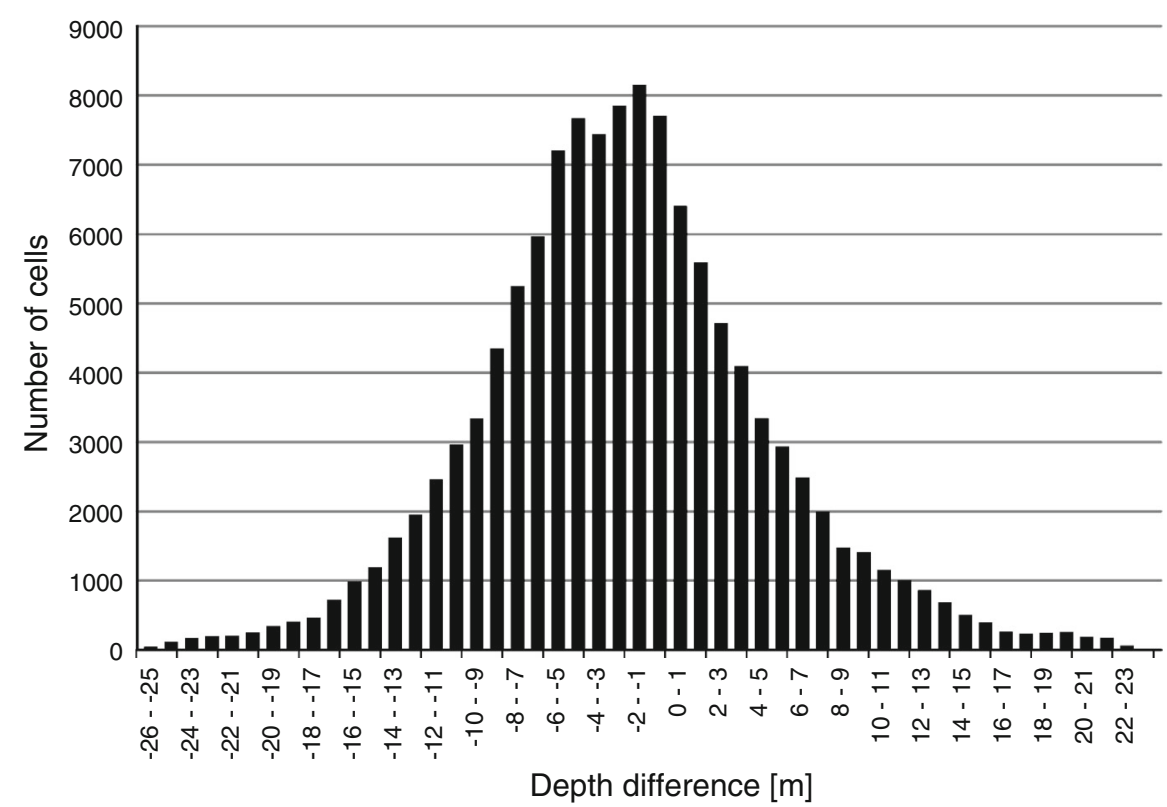

Figure 6

Spatial distribution of depth differences between historical survey in 1930 and the new hydroacoustic measurements in 2010-2011

Model (OGC Reference Model 2011) that describes the relationships of OGCs baseline products.

Due to the cost and technical requirements, a universal solution has been proposed. In the most advanced form this will be a hybrid solution merging proprietary software from ESRI and open-source products. This gives a robust system with many options to acquire, manage, analyze, visualize and share spatial data. A simpler solution could realize only a specific task, for example, a map server rule to share data with OGC standards. The system architecture is presented in Fig. 7.

\subsection{System Architecture, Capabilities and Performance}

The central part of the system consists of a Spatial Database Management System (SDBMS). The SDBMS is responsible for most tasks related with: data modeling, data load capability, security, controlled updates, backup and recovery and administration tools. The author's proposition for Lake Hancza implementation is to select one of the two well-known, marketleading DBMS products. A proprietary Oracle database with a spatial extension (Oracle Spatial) or the free-ofcharge PostgreSQL with the PostGIS extension are under consideration. The database can be managed from one of the popular desktop GIS applications. With ESRI ArcGIS there is also a need for middleware between the DBMS and GIS application (typically, ArcSDE or ZigGIS). Quantum GIS (QGIS) can access a PostgreSQL database natively.

The role of the Map Server is usually providing interactive Web mapping access to collections of digital geospatial data. Typical Map Server products for the publication of maps via Web Services are ESRI ArcGIS Server, MapServer, GeoServer or QGIS Map Server. All of them implement standard open web protocols, OGC and other spatial standards. They contain a compliant Web Map Service (WMS), Web Feature Service (WFS) and Web Coverage Service (WCS) standards, and implementation of the Geography Markup Language (GML)/Keyhole Markup Language (KML) standard format.

\subsection{Bathymetric Database Implementation}

One of the primary objectives of this research was to develop the Lake Hancza bathymetric database. The proposed solution is easy to implement and compatible with international standards. This allows users to combine shared bathymetric data with maps, 


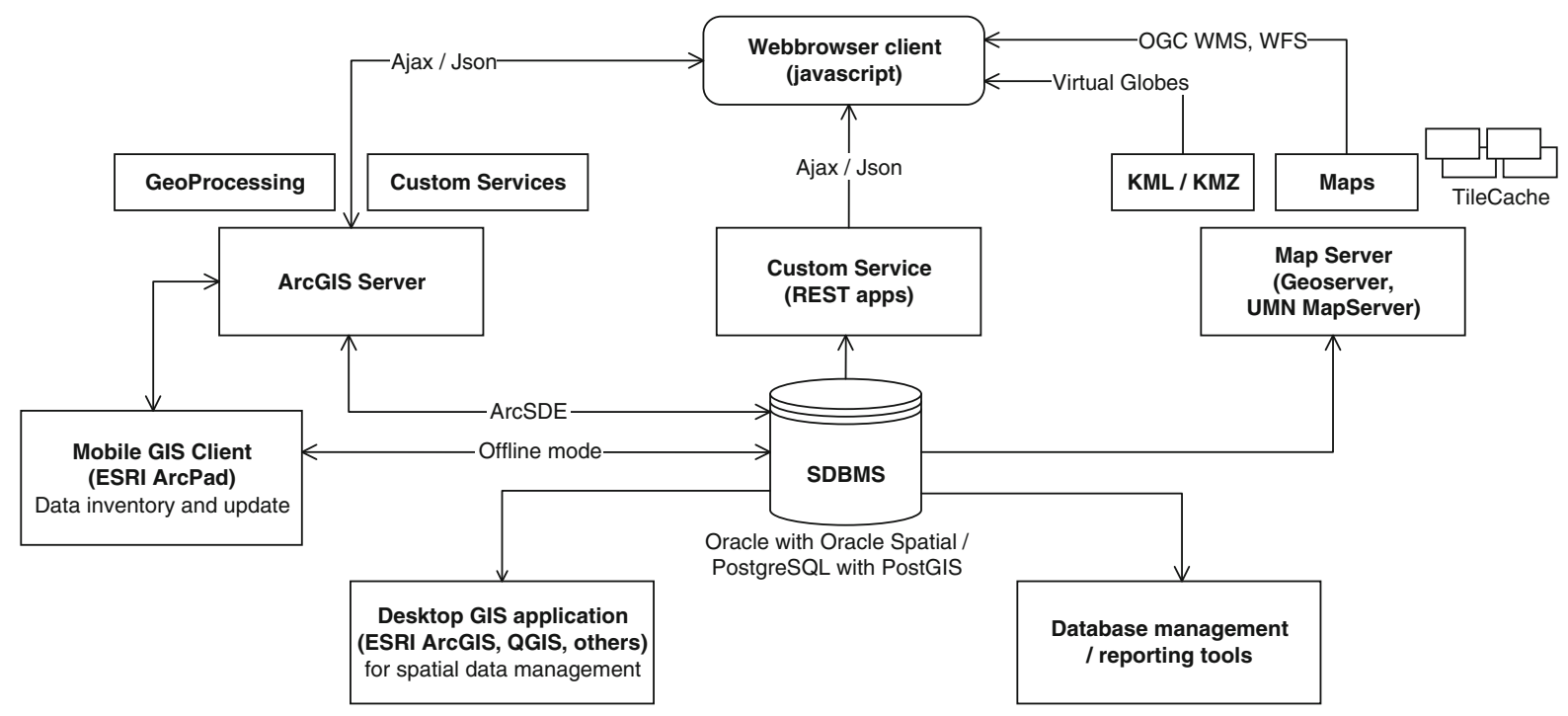

Figure 7

Database system architecture

spatial databases and geo-services generated by GIS servers from different sources available on the Internet. This study presents the process of preparing the new spatial database structure and publishing the spatial data described in the first sections. The previously-described solution for building the information system on Lake Hancza was used. A commercial off-the-shelf desktop ArcGIS product was chosen to manage the spatial database. Open source technology was used to store data and publish the context of spatial information over the Internet with OGC standards.

PostgreSQL with the PostGIS extension was used to store spatial and non-spatial data. The OGR Simple Feature Library/GDAL (Geospatial Data Abstraction Library) utilities were used to convert the ESRI Personal Geodatabase into PostgreSQL tables. The new database was then customized for web-based retrieval, analysis and visualization of spatiallyrelated environmental data. All spatial tables were published with a GeoServer map server as WMS/ WCS/WFS services. Some data in the KML format was also published to present the spatial context using Virtual Globes.

The proposed solution guarantees integration with various spatial web services from diverse institutions and scientific databases, such as geological studies, hydrological data, geodetic and cadastral databases, topographic maps, satellite imagery, aerial photos and others. Thus, many services are in standard WMS and WCS, while services in standard Representational State Transfer (REST) are integrated, guaranteeing a good degree of interoperability and sharing.

The proposed architecture also includes the ability to update the database using mobile GIS technology. Mobile GIS is the use of geographic data in the field on mobile devices. Mobile GIS integrates three essential components; GNSS, rugged handheld computers and GIS software. Bringing these technologies together makes the database directly accessible to field-based personnel. Typical examples of mobile GIS applications include studies of coastline changes and the location of inshore hydrotechnical objects (Templin and Popielarczyk 2011).

\section{Results}

The deepest reservoir in Poland-Lake Hancza is the subject of ongoing environmental studies. The historical depth measurements were collected in July 1930. This raw data was used to elaborate a bathymetric plan and calculate the basic morphometric data. The results of this work were published in 1932 by Professor Ruhle. The maximum depth was $108 \mathrm{~m}$, 
referenced to a water surface level of $227.2 \mathrm{~m}$ above sea level. According to the new hydroacoustic and geodetic measurements 35,797 data points were used to create the Lake Hancza DEM. The maximum depth was $105.7 \mathrm{~m}$ with $227.6 \mathrm{~m}$ of the water level above sea level. For analysis, both sets of data were reduced to the common water level.

Further analysis of an old analogue map and the new bathymetry shows the changes in the bottom shape. In part, this is due to small amounts of measurement raw data collected in 1930. Ruhle took 356 soundings while 35,797 were collected during the last survey (Fig. 4). Additionally, the depth differences histogram shows significant changes of the bottom DEM (Figs. 5, 6).

The Ruhle bottom shape was clearly lower than the new shape measured by authors. This indicates some geomorphological changes over time. The differences between the shape of old and new lake bottom tell us about the physical changes occurring over the last few decades. By analyzing in detail a description of the work of Professor Ruhle, he described the bottom in the deepest region of the lake as being hard with sand and gravel. An analysis of the low frequency echograms from SBES surveys show that on the bottom there is a layer of sediment. The difference in the maximum depth of the lake which was observed between the historical and contemporary measurements may be due to the deposition of organic matter on the bottom of Lake Hancza. To confirm this hypothesis, a hydroacoustic sub-bottom profiler with a very low frequency should be used to investigate the layer under the Lake Hancza bottom.
It should also be noted that there is no record of how the reference water level above the sea was calculated in 1930. This aspect has a crucial impact on the value of the maximum depth of the lake. The lake water level should be necessarily represented in relation to the mean sea levels or geodetic vertical reference system. Ruhle reports that the Lake Hancza mean water level in 1930 was $227.2 \mathrm{~m}$ above sea level. Contemporary GNSS/hydroacoustic measurements were related to vertical map datum in Poland (normal heights above sea level, Kronsztadt'86).

The described results show significant differences in the shape of the lake bottom, compared to historical data. These may be an important factor for many researchers and have implications for research in many areas.

\section{Discussion}

The inland water reservoirs in Poland consist of lakes, rivers and channels. There are also many shallow estuaries-usually lakes. Most of them do not have recently updated analogue or digital charts and some were measured 50-60 years ago. The existing analogue bathymetric plans do not accurately present the bottom topography. Therefore, it is crucial to explore their bottom DEM to ensure safety by creating new bathymetric charts and digital bottom visualizations, marking the inland waterways and dangerous regions (PoPIELARCZYK and OsZCZAK 2006). Recent bathymetric data are also needed for research in the following scientific fields: hydrobiology,

Table 1

Specifications for Lake Hancza surveys

\begin{tabular}{|c|c|c|c|c|c|c|c|c|c|}
\hline \multirow[t]{2}{*}{ Stage } & \multirow[t]{2}{*}{ Date } & \multirow{2}{*}{$\begin{array}{l}\text { No. of } \\
\text { points }\end{array}$} & \multicolumn{2}{|c|}{ Water conditions } & \multicolumn{2}{|c|}{ Hydrographic system } & \multicolumn{2}{|l|}{ Positioning } & \multirow{2}{*}{$\begin{array}{l}\text { Water level } \\
\text { Kronsztadt'86 } \\
\text { (m) }\end{array}$} \\
\hline & & & $\begin{array}{l}\text { Temperature } \\
\left({ }^{\circ} \mathrm{C}\right)\end{array}$ & $\begin{array}{l}\text { Sound } \\
\text { speed }(\mathrm{m} / \mathrm{s})\end{array}$ & SBES & $\mathrm{kHz}$ & GPS receivers & GNSS & \\
\hline 1 & $\begin{array}{c}\text { May } 18-19, \\
2010\end{array}$ & 11,976 & $13.12-4.27$ & $1,458-1,422$ & Simrad EA501P & 200 & $\begin{array}{c}\text { Thales Mobile Mapper } \\
\text { Topcon HiPer Pro }\end{array}$ & $\begin{array}{l}\text { DGPS } \\
\text { RTK }\end{array}$ & 227.90 \\
\hline 2 & $\begin{array}{l}\text { March 12, } \\
2011\end{array}$ & 12 & $0.86-3.30$ & $1,406-1,418$ & $\begin{array}{l}\text { Simrad EA501P } \\
\text { Reson NS 515 }\end{array}$ & $\begin{array}{l}200 \\
200 / 33\end{array}$ & Topcon HiPer Pro & Static & 227.60 \\
\hline 3 & $\begin{array}{c}\text { May 6-8, } \\
2011\end{array}$ & 23,821 & $8.00-4.00$ & $1,438-1,421$ & Reson NS 515 & $200 / 33$ & $\begin{array}{c}\text { Thales Mobile Mapper } \\
\text { Topcon HiPer Pro }\end{array}$ & $\begin{array}{l}\text { DGPS } \\
\text { RTK }\end{array}$ & 227.65 \\
\hline
\end{tabular}


limnology, fisheries, water biology, etc. This is the main reason why the authors present a practical solution to collect, process, analyze and share bathymetric data.

The dynamic growth of satellite positioning systems, hydroacoustic measurement technology and the increasing availability of measuring devices provide new potential to develop integrated measurement solutions. This gives the opportunity to reduce data acquisition costs and improve the quality of new developments.

One of the advantages presented by integrated GNSS/hydroacoustic measurement technology is not only the creation of bathymetric products but also the concept of architecture to publish measurement results using technologies with platforms based on hybrid solutions combining commercial and free software. Depending on the user requirements, they can choose software tools with licenses that best meet the assumed criteria. The proposed solution involves using a Geoserver to generate web services in standard OGC, including WMS, WFS and WCS. These standards guarantee the sharing of basic bathymetric products with other users and providing access to this data with a GIS application, OGC web services client or Virtual Globe through the overlay of layers. Figure 8 shows the location of water sampling points for physicochemical analysis designed on the new DEM.

The architecture presented in this paper proposes a solution of rapid acquiring, implantation and availability of bathymetric data through the web, with a set of web services made available to easily integrate the data. The next step is to create a WebGIS interface and implement the proposal architecture with an ESRI API.

\section{Conclusions}

Due to the geomorphology of the lake, chemical and biological characteristics of the aquatic environment, the lake is still a subject of interest of scientists from many disciplines. Current studies are still based on old bathymetric maps. The described results of the Lake Hancza bottom analysis show significant changes over the last few decades. Therefore, the authors decided to share the latest hydrographic

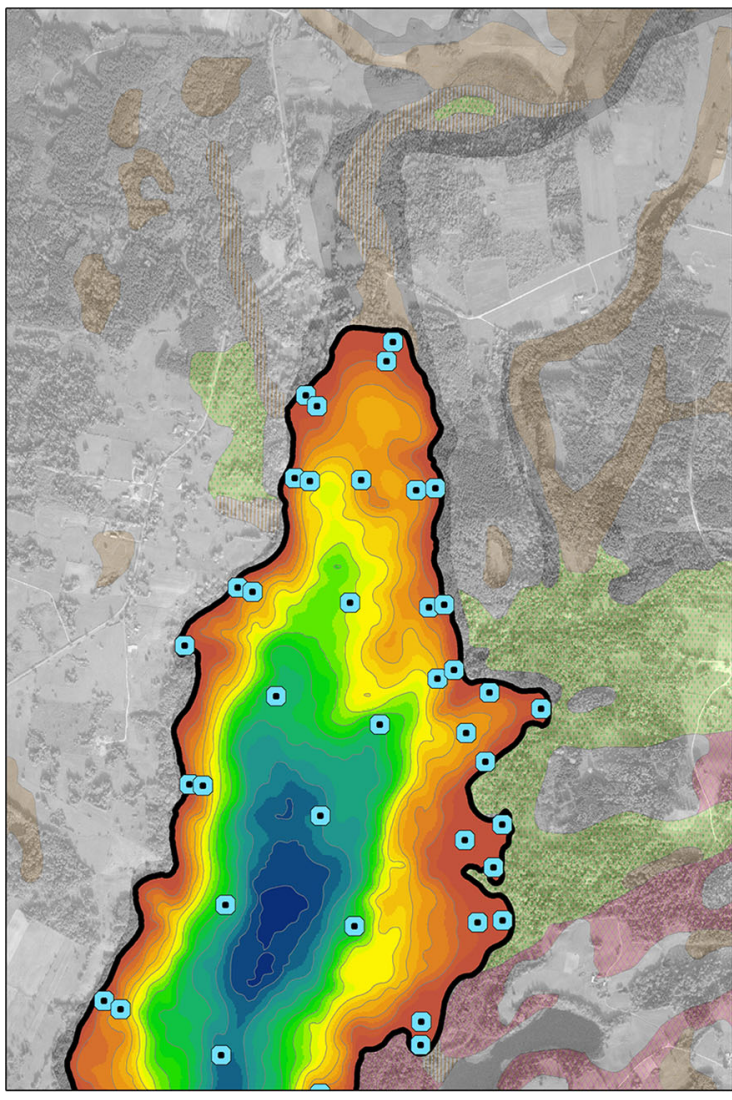

Figure 8

Location of water sampling points

research with the use of the network web services standard. It allows the direct use of these results and their integration with environmental projects realized by researchers in the field of geomorphology, limnology, hydrobiology, fishery, etc.

Modern measuring techniques, such as GNSS, Multi-Beam Echo Sounder, radar and laser scanning bring new opportunities for acquisition and bathymetric raw data processing. The example of Lake Hancza shows that the newly-collected bathymetric data visualized as DEMs in the presented database can be used in further scientific studies. The proposed geodatabase system architecture provides a universal solution which can be used not only by researchers, but also by divers, sailors, fishermen and emergency services.

The authors demonstrate examples of how to build an open and flexible solution using proprietary or open source GIS tools. Both of them include 
expanded support for OGC standards, such as WMS, WCS and Transactional WFS (WFS-T). International OGC standards are a significant step towards cooperating and exchanging data between researchers and engineers in many fields.

\section{Acknowledgments}

The authors would like to thank students from University of Warmia and Mazury in Olsztyn, who helped with bathymetric surveys and raw data elaboration, inparticular Lech Majewski, Jarosław Rydzewski, Adrian Gonzales Moreno, Edyta Podziewska and Paweł Jarzębowski. The Laka Hancza research has been partly supported by grant from the Ministry of Science and Higher Education (contract No. N N526 227339). Special thanks to the community Przerosl for sponsoring the cost of third stage field measurements.

Open Access This article is distributed under the terms of the Creative Commons Attribution License which permits any use, distribution, and reproduction in any medium, provided the original author(s) and the source are credited.

\section{REFERENCES}

BaKUla, M. 2010, Network code DGPS positioning and reliable estimation of position accuracy, Survey Review, 42 (315), pp. 82-91.

Bosy, J., Graszka, W., Leończyk, M. 2007, ASG-EUPOS - A Multifunctional Precise Satellite System in Poland, European Journal of Navigation, 5 (4), pp. 2-6.

Breunig, M., Zlatanova, S. 2011, 3D geo-database research: Retrospective and future directions, Computers \& Geosciences 37, pp. 791-803.

Cannon, M. E., Lachapelle, G., Fortes, L. P., Alves P., Townsend, B. 2001, The Use of Multiple Reference Station VRS for Precise Kinematic Positioning, proceedings of the Japan Institute of Navigation, GPS Symposium 2001, Tokyo, pp. 29-37.

Chesnaux, R., Lambert, M., Walter, J., Fillastre, U., Hay, M., Rouleau, A., Daigneault, R., Moisan, A., Germaneau, D. 2011, Building a geodatabase for mapping hydrogeological features and $3 D$ modeling of ground water systems: Application to the Saguenay-Lac-St.-Jean region, Canada, Computers and Geosciences 37 (11), pp. 1870-1882.

Chien, N.Q., Keat Tan, S. 2011, Google Earth as a tool in 2-D hydrodynamic modeling, Computers and Geosciences 37 (1), pp. 38-46.

Ciecko, A., Oszczak, B., Oszczak, S. 2006, Efficient and CostEffective Generation of Precise Digital Terrain Model (DTM) with the Use of GPS and GSM/GPRS Technology, proceedings of the 2006 National Technical Meeting of the Institute of Navigation - NTM 2006, pp. 490-496.

Clarke, J. E. H. 1996, Shallow-Water Imaging Multibeam Sonars: A New Tool for investigating Seafloor Processes in the Coastal Zone and on the Continental Shelf, Marine Geophysical Researches, 18, Issue 6, pp. 607-629.

Clay, C. S., Medwin, H. 1977, Acoustic Oceanography: principles and applications, John Wiley \& Sons, New York.

Darbyshire, J., Edwards, A. 1972, Seasonal formation and movement of the thermocline in lakes, Pure and Applied Geophysics 93, No. 1, pp. 141-150.

El-Sheimy, N., Valeo, C., Habib, A. 2005, Digital Terrain Modeling - Acquisition, Manipulation and Applications, Artech House Inc., Norwood.

Hawley, J. H. 1931, Hydrographic Manual, U. S. Coast and Geodetic Survey, Special Publication No. 143, United States Government Printing Office, Washington.

Heritage, G. L., Milan D. J., Large, A. R. G., Fuller, I. C. 2009, Influence of survey strategy and interpolation model on DEM quality, Geomorphology 112, pp. 334-344.

Hollister, J., Milstead, W. B. 2010, Using GIS to estimate lake volume from limited data, Lake and Reservoir Management, Vol. 26, Issue 3, pp. 194-199.

Hollister, J., Milstead, W. B., Urrutia, M. A. 2011, Predicting Maximum Lake Depth from Surrounding Topography, PLoS One, 6, Issue 9, pp. 1-6.

Hutchinson, M. F. 1989, A new method for gridding elevation and streamline data with automatic removal of pits, Journal of Hydrology 106, pp. 211-232.

Hutchinson, E. G. 1957, A Treatise on Limnology. Volume 1, Part 1: Geography and Physics of Lakes. John Wiley \& Sons, Inc., New York.

Hydrographic Surveys Division 1878, Inshore Hydrographic Work of the Coast Survey, General Instructions, Government Printing Office, Washington.

InGHAM, A. E. 1992, Hydrography for the Surveyor and Engineer, 3rd edition Revised by V. J. Abbott, Blackwell Science Ltd, Oxford.

InTERNATIONAL HydrograPhic ORganization 1994, IHO Hydrographic Dictionary, Special Publication No 32, 5th Edition, International Hydrographic Bureau, Monaco.

InTERNATIONAL HydrograPhic ORganization 2005, IHO Hydrographic Manual, Publication C-13, 1st Edition, International Hydrographic Bureau, Monaco.

International HydrogRaPhic ORganization 2008, IHO Standards for Hydrographic Surveys, Special Publication No 44, 5th Edition, International Hydrographic Bureau, Monaco.

Jozsa, V., Tatrai, I., Gyore, K. Kozlowski, J. 2008, Bathymetric profile of Lake Hancza, in Environment and ichtiofauna of Lake Hancza (ed. Kozłowski, J., Poczyczyński, P., Zdanowski, B.), Inland Fisheries Institute, Olsztyn, pp. 43-58 [in Polish].

Kim, Y. S., Lee, D. M., Hong, S. H., Chung, Ch. S., Lee, K. W. 2008, Coastline change analysis using RTK-GPS and aerial photo, The International Archives of the Photogrammetry, Remote Sensing and Spatial Information Sciences, Beijing, Vol. XXXVII, Part B8, pp. 689-694.

Kresse, W., Danko, D. M. 2012, Handbook of Geographic Information, Springer.

Kulawiak, M., Prospathopoulos, A., Perivoliotis, L., Luba, M., Kioroglou, S., Stepnowski, A. 2010, Interactive visualization of 
marine pollution monitoring and forecasting data via a Webbased GIS, Computers and Geosciences 36 (8), pp. 1069-1080.

LEon, J.X., CoHEN, T.J. 2012, An improved bathymetric model for the modern and palaeo Lake Eyre, Geomorphology 173-174, pp. 69-79.

Longley, P. A., Goodchild, F. M., Maguire, D. J., Rhind, D. W. 2011, Geographic Information Systems \& Science, Third Edition, John Wiley \& Sons Inc., Hoboken, New Jersey.

Moore, I. D., Grayson, R. B., Ladson, A. R. 1991, Digital terrain modeling: a review of hydrological, geomorphological, and biological applications. Hydrol. Processes 5, pp. 3-30.

National Oceanic AND Atmospheric Administration 1976, Hydrographic Manual, Fourth Edition, NOAA, U.S. Department of Commerce, National Ocean Survey, Rockville.

OGC Reference Model v. 2.0 2011, https://portal.opengeospatial. org/files/?artifact_id=47245.

Popielarczyk, D., Oszczak, S. 2006, Application of Integrated Satellite DGPS/GPRS Navigation and Hydrographic Systems for Safe Sailing on Great Mazurian Lakes in Poland, proceedings of the 2006 National Technical Meeting of the Institute of Navigation - NTM 2006, pp. 188-194.

PopielarczyK, D. 2011, Application of global navigation satellite system and hydroacoustic techniques to safety of inland water navigation, Archives of Transport 23 (2), pp. 191-207.

PopielarcZYK, D. 2002, Application of Integrated GPS and Single Beam Echosounder Systems for Creation of Electronic Charts of Inland Water Reservoirs, Ph.D. dissertation, University of Warmia and Mazury, Olsztyn [in Polish].

Popielarczyk, D., Oszczak, S. 2002, Determination of accuracy of boat positioning during bathymetric survey, proceedings of the European Navigation Conference, GNSS 2002, Copenhagen.

Ruhle, E. 1932, Der Hancza See auf der Suwalken-Seeplatte, Geographic Messaging Service, Vol. 6, No. 4, pp. 422-455.
Ryczywolski, M., Oruba, A., Leończyk, M. 2008, The precise satellite positioning system ASG-EUPOS, proceedings of International Conference GEOS 2008, Prague.

SheKhar, S., XIOng H. 2008, Encyclopedia of GIS, Springer.

Shiklomanov, I. A., Rodda, J. C. 2003, World water resources at the beginning of the 21st century, Cambridge University Press, Cambridge.

SLEDZINSKI, J. 1927, The lakes of Suwalki district, Archives of Hydrobiology and Fisheries, Vol. III, No. 1-2, Suwalki [in Polish]. STANGENBERG, M. 1936, Limnologische Charakteristik der Seen des Suwatki-Gebiets auf Grund der hydrochemischen Untersuchungen, Department of Ichthyobiology and Fishery, Warsaw University of Life Sciences - SGGW, No. 43, pp. 7-85.

STANGENBERG, M. 1938, The chemical composition of deep-sea sediments of lakes in Suwalki district, Forest Research Institute, Vol. A, No. 31, pp. 1-44 [in Polish].

Templn, T., Popielarczyк, D. 2011, Investigation of Coastline Changes and Inshore Hydrotechnical Objects Location Using GNSS Technology, Reports on Geodesy, No. 1(90), pp. 485-493.

Tsou, M.-H. 2004, Integrating web-based GIS and image processing tools for environmental monitoring and natural resource management, Journal of Geographical Systems 6 (2), pp. 155-174.

US Army Corps of Engineers 2003, Engineering and Design Hydrographic Surveying, Manual EM 1110-2-1003, Department of the Army, Washington.

YAnG, X., Zhang, T. 2011, Detecting Estuarine Bathymetric Changes with Historical Nautical Data and GIS in Geoinformatics in Applied Geomorphology (ed. Anbazhagan, S., Subramanian, S. K., Yang X.), CRC Press Taylor \& Francis Group, Boca Raton, Florida, pp. 105-117.

Yeung, A.K.W., Brent, H.G. 2007, Spatial Database Systems: Design, Implementation and Project Management, Springer, AA Dordrecht, The Netherlands. 